\title{
A phase 1 study of the BCL2-targeted deoxyribonucleic acid inhibitor (DNAi) PNT2258 in patients with advanced solid tumors
}

\author{
Anthony W. Tolcher $\cdot$ Wendi V. Rodrigueza $\cdot$ Drew W. Rasco $\cdot$ Amita Patnaik $\cdot$ \\ Kyriakos P. Papadopoulos • Alex Amaya · Timothy D. Moore · Shari K. Gaylor • \\ Charles L. Bisgaier · Mina P. Sooch · Michael J. Woolliscroft · Richard A. Messmann
}

Received: 18 July 2013 / Accepted: 13 November 2013 / Published online: 3 December 2013

(C) The Author(s) 2013. This article is published with open access at Springerlink.com

\begin{abstract}
Purpose Maximum tolerated dose, safety, pharmacokinetics, and pharmacodynamics were assessed in this phase 1 study of PNT2258, a BCL-2-targeted liposomal formulation of a 24-base DNA oligonucleotide called PNT100.

Methods Patients with malignant solid tumors were assigned sequentially to one of ten dose-escalation cohorts of PNT2258 at 1, 2, 4, 8, 16, 32, 64, 85, 113, and $150 \mathrm{mg} /$ $\mathrm{m}^{2}$ administered intravenously on days 1 through 5 of each 21-day cycle. Pharmacokinetics were determined on days 1 and 5 of the first cycle. Lymphocyte and platelets concentrations were measured for evidence of BCL2-targeted effect. CT scans were used to identify radiologic evidence of anti-tumor effect.

Results Twenty-two subjects received PNT2258, and the maximum tolerated dose for PNT2258 was not reached. Doses at or above $32 \mathrm{mg} / \mathrm{m}^{2}$ resulted in exposure to PNT2258 above the exposure level required for anti-tumor activity in preclinical xenograft testing of $22,377 \mathrm{ng} \mathrm{h} /$ $\mathrm{ml}$ (PK analysis 2012). Fatigue was the most commonly reported adverse event. Dose-limiting toxicity, manifesting as a transient increase in aspartate aminotransferase, occurred at $150 \mathrm{mg} / \mathrm{m}^{2}$, the highest dose tested. Four
\end{abstract}

A. W. Tolcher · D. W. Rasco - A. Patnaik - K. P. Papadopoulos · A. Amaya

South Texas Accelerated Research Therapeutics (START), LLC, San Antonio, TX, USA

W. V. Rodrigueza · S. K. Gaylor · C. L. Bisgaier · M. P. Sooch · M. J. Woolliscroft · R. A. Messmann $(\square)$ ProNAi Therapeutics, Inc., 46701 Commerce Center Dr., Plymouth, MI 48170, USA

e-mail: rmessmann@pronai.com

T. D. Moore

Mid-Ohio Oncology Hematology, Inc., Columbus, OH, USA subjects, two each with diagnosis of non-small-cell lung cancer and sarcoma, treated at doses of $64 \mathrm{mg} / \mathrm{m}^{2}$ or higher, remained on study for 5-8 cycles.

Conclusions PNT2258 was safe and well tolerated at the doses tested up to $150 \mathrm{mg} / \mathrm{m}^{2}$. Exposure to PNT2258 resulted in clinically manageable decreases in lymphocyte and platelet concentrations.

Keywords PNT2258 - Phase I - DNAi .

Deoxyribonucleic acid inhibitor $\cdot$ BCL2 $\cdot$ Liposome

\section{Introduction}

BCL2 and its related family of proteins play a key and central role during embryogenesis, homeostasis, as guardians of mitochondrial function, and in the regulation of apoptosis and autophagy subsequent to cellular injury or stress [1-3]. The derangement of BCL2 regulated control mechanisms is a defining characteristic of certain malignancies including subsets of non-Hodgkin's lymphoma (NHL) and chronic lymphocytic leukemia [4].

This phase 1 study is the first-in-human assessment of PNT2258. The primary endpoints of the study included identification of the maximum tolerated dose of PNT2258 and characterization of the safety and toxicity profile of PNT2258 when administered to patients with advanced solid tumors. Secondary objectives included characterization of the PNT2258 pharmacokinetic profile and identification of any anti-tumor effect that may occur. The exploratory objective for the study included analysis of peripheral blood mononuclear cells (PBMCs), lymphocyte and platelet concentrations, plasma and serum samples for evidence of BCL2-mediated effect. 


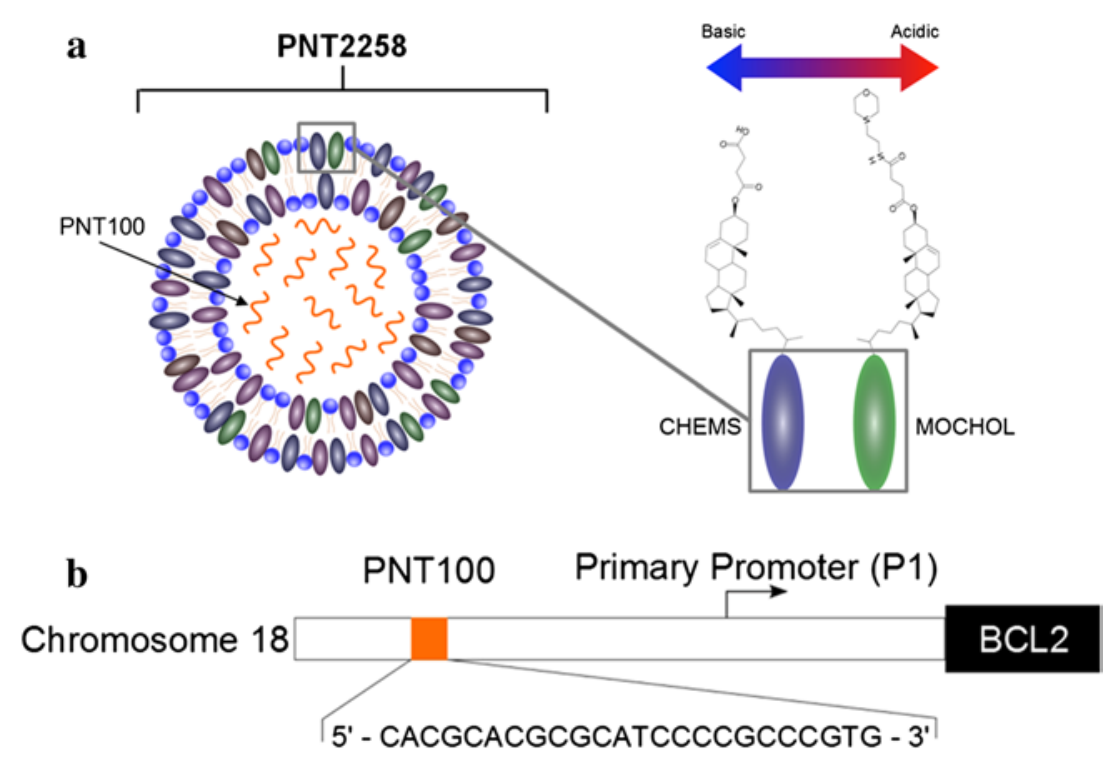

Fig. 1 a A representation of the PNT2258 molecule. The PNT100 oligonucleotide is encapsulated in liposomes of MOCHOL/CHEMS/ DOPE/POPC, particle size $\sim 130 \mathrm{~nm}$. PNT2258 has an overall pKa of $\sim 6.5$, containing $\mathrm{pH}$ responsive lipids that are cationic during manufacturing (in order to attract the negatively charged PNT100 oligonucleotide) and anionic during systemic circulation. Charge

\section{PNT2258}

PNT2258, the anti-BCL2 experimental therapeutic used in this study, consists of a protective liposomal formulation composed of four lipids encapsulating a 24-base, chemically unmodified DNA oligonucleotide called PNT100. A representation of the PNT2258 molecule is illustrated in Fig. 1a. The lipid components of this PNT2258 nanoparticle are comprised of 1-palmitoyl-2-oleoyl-snglycero-3-phosphocholine (POPC), 1,2-dioleoyl-snglycero-3-phosphoethanolamine (DOPE), cholesteryl hemisuccinate (CHEMS), and cholesteryl-4-([2-(4-morpholinyl)ethyl]amino)-4-oxoburanoate (MOCHOL) [5]. These nanoparticles are anionic at physiological $\mathrm{pH}$, and their specific lipid ratio imparts a "pH-tunable" character and a charge to the liposomes, which changes depending upon the surrounding $\mathrm{pH}$ of the microenvironment to facilitate movement across physiologic membranes [6, 7]. The PNT2258 nanoparticle is sized to avoid extensive hepatic sequestration, with an average diameter of approximately $130 \mathrm{~nm}$, facilitating systemic distribution and serum stability after intravenous injection [8]. These specialized liposomes are also known by the registered trade name as SMARTICLES ${ }^{\circledR}$.

Preclinical studies of injected PNT2258 demonstrated systemic biodistribution of the active pharmaceutical ingredient (PNT100) with accumulation into tissues including xenograft tumors [9]. and lipid components are similar to circulating lipoproteins The $\mathrm{pH}$ "tunability" is designed to enhance endosomal escape following cellular uptake. b Diagrammatic representation of the DNA "target" for PNT100 binding located on chromosome 18. The PNT100 oligonucleotide sequence is designed to hybridize (i.e., bind) to a region $5^{\prime}$ upstream of the BCL2 gene start site

PNT100 is a single-stranded DNA 24-base oligonucleotide encapsulated in the aqueous core within the liposomal nanoparticle. PNT100 is a solid-phase on-column chemically synthesized oligonucleotide that is cleaved from the column solid support, followed by ion-exchange (IEX) purification, ultra-filtration/diafiltration (UF/DF), and concentration with subsequent freeze-drying. PNT100 has the sequence, 5'-CACGCACGCGCATCCCCGCCCGTG-3'. PNT100 is specific to regulation of the BCL2 gene and not designed to hybridize to the regulatory areas of other BCL2 protein family members such as Bcl-xL, MCL-1, or Bcl-w. HeLa cells exposed to Cy5.5-fluorescently labeled liposomal encapsulated PNT100 showed fluorescence concentrated in nuclei with diffuse perinuclear distribution [10].

The PNT100 sequence is designed to hybridize with genomic sequences that reside within $5^{\prime}$-untranscribed regulatory regions of the BCL2 gene to block transcription of BCL2 through a mechanism called DNA interference (DNAi) (Fig. 1b). In cancerous cells and in contrast to normal cells, these upstream regulatory regions are susceptible to hybridization by having an open chromatin state that occurs during oncogene up-regulation [11]. Additionally, the PNT100-targeted area of the genome is included in translocation $t(14,18)$ [12]. The interaction of the PNT100 DNAi oligonucleotide with the targeted non-coding, non-transcribed genomic DNA was designed to block 
transcription and silence BCL2 transcription, prompting initiation of the cell death pathway and pro-apoptotic events that lead to cancer cell death.

\section{Preclinical studies}

Liposomal formulations of PNT100 given IV have demonstrated dose-dependent, single-agent efficacy, including complete and partial tumor regressions and extended tumor growth delays in a WSU-DLCL2 murine xenograft model of human NHL [13]. In addition, synergistic in vivo anti-tumor effect was noted with liposomal PNT100 in combination with rituximab or docetaxel in xenograft models of human Burkitt's lymphoma and melanoma, respectively [8].

Anti-tumor effects in mice bearing WSU-DLCL2 NHL xenograft tumors were only observed when the animals received liposomal PNT100, but not a liposomal formulation of either a scrambled 24-base control or a 2-base mismatch oligonucleotide (i.e., differing in sequence from PNT100 at 2-bases). These results suggest that a sequencespecific genomic interaction contributed to the DNAi mechanism of action.

The preclinical pharmacokinetic characterization of PNT2258 consisted of analyzing PNT100 concentration, the active oligonucleotide ingredient in rodent and primate plasma obtained from a toxicity and safety pharmacology study. In this study, PNT2258 was administered for 5 consecutive days during two cycles separated by 2 weeks $[14,15]$. PNT100 was detected by a hybridization-ligation assay after detergent disruption of the PNT2258-containing plasma samples. The probe used in the assay was specific for full-length human PNT100. The non-competitive hybridization and ligation assay (by ELISA) was validated in monkey plasma and cross-validated in human plasma (including interference for hemolysis) and was used in this study [16]. No free PNT100 was detected in the samples prior to detergent disruption of the lipid nanoparticle. The data obtained from measurement of monkey plasma PNT100 concentration demonstrated greater than doseproportional exposure and an apparent multi-compartmental and saturable clearance process. The clearance of the PNT2258 liposomes from circulation was presumed to be mediated by mononuclear phagocytes residing primarily in the spleen and liver (Kupffer cells) as visualized during histopathology in the toxicology studies in both cynomolgus monkeys and rats $[14,15,17]$. The tissue distribution is consistent with other known liposomal formulations [18].

\section{Human study dose selection}

In addition to the cynomolgus monkeys, rats were used as the second species for PNT2258 preclinical toxicity studies.
A lowest no observed-adverse effect level (NOAEL) for PNT2258 was defined at $15 \mathrm{mg} / \mathrm{kg} /$ day in rats and $16 \mathrm{mg} /$ $\mathrm{kg}$ /day in monkeys. The IV starting dose of PNT2258 in the clinical phase 1 study was $1.0 \mathrm{mg} / \mathrm{m}^{2}$, representing $1 / 6$ th the NOAEL in rats based on a corresponding human body surface area of $1.6 \mathrm{~m}^{2}$.

\section{Materials and methods}

Patient selection

The study population included only patients with metastatic solid tumors that had exhausted standard therapeutic options; were age $\geq 18$ years; and had Eastern Cooperative Oncology Group performance status $\leq 2$ with adequate bone marrow, hepatic, and renal function. As this was a pilot dose finding and toxicity-characterization phase 1 study, pre-identification of patients on the basis of their existing BCL2 tumor status was not a requirement for study participation. All subjects provided written informed consent.

The trial was conducted in accordance with precepts established by the Helsinki Declaration. The institutional review board approved the protocol, and the study was registered at ClinicalTrials.gov and given the identifier number of NCT01191775 [19].

\section{Study design and treatment schema}

PNT2258 was supplied in $20 \mathrm{~mL}$ vials (with a target concentration of $2.5 \mathrm{mg} / \mathrm{mL}$ PNT100) and kept frozen $\left(-20 \pm 5{ }^{\circ} \mathrm{C}\right)$ during storage. PNT2258 was allowed to thaw at room temperature and subsequently diluted in $200 \mathrm{~mL}$ of $0.9 \%$ sodium chloride in preparation for IV administration. Patients received PNT2258 as a 2-hour IV infusion, once daily on days 1-5 of a 21-day cycle. Individual patient doses were calculated based upon body surface area (with capping at a maximum of $2 \mathrm{~m}^{2}$ ) obtained prior to dosing on C1D1 with an allowed adjustment in dose for $\geq 10 \%$ change in body weight during the study.

The initial dose level (i.e., cohort 1 ) was $1 \mathrm{mg} / \mathrm{m}^{2}$. Doses 1 through $64 \mathrm{mg} / \mathrm{m}^{2}$ allowed 1 patient per cohort until the occurrence of a dose-limiting toxicity (DLT), triggering cohort expansion to 3 patients. Doses 85 through $150 \mathrm{mg} /$ $\mathrm{m}^{2}$ required 3 patients per cohort until the occurrence of a DLT. Assuming 0-1 DLTs at any dose level, patients were treated at the next higher dose level. If at any time 2 or more patients developed DLTs within a dose level, the level was considered too toxic, and the next lowest dose level was considered the recommended phase 2 dose.

All toxicities, regardless of attribution, were considered in determining whether a DLT had occurred at any 
particular dose and DLT was defined as any of the following events experienced during cycle 1: grade 4 neutropenia of $>5$ days duration or grade 3 or greater febrile neutropenia of any duration; grade 4 thrombocytopenia; any grade 3 or greater non-hematologic toxicity (except alopecia, nausea/vomiting well controlled with antiemetics, and laboratory abnormalities felt to be clinically insignificant or that were elevated at baseline); any toxicity resulting in a treatment delay of $>2$ weeks; an acute infusion reaction that did not resolve to baseline or $\leq$ grade 1 after infusion interruption and resumption at a slower rate; a 2-grade increase in AST (SGOT)/ALT (SGPT) for patients with baseline grade 1 or 2 abnormalities. The maximum tolerable dose (MTD) was defined prospectively as the dose level below the dose where $\geq 2$ of 6 patients experienced DLT.

Sequential cohort doses were doubled (i.e., 1, 2, 4, 8, 16 and $32 \mathrm{mg} / \mathrm{m}^{2}$ ) until the $64 \mathrm{mg} / \mathrm{m}^{2}$ dose level; thereafter, dose escalation proceeded in $33 \%$ dose increments from 85 to $113 \mathrm{mg} / \mathrm{m}^{2}$ and to a final dose of $150 \mathrm{mg} / \mathrm{m}^{2}$.

\section{Baseline and treatment assessments}

Baseline and on study assessments included medical history, physical examination, vital signs, ECOG performance status, ECG, radiographic tumor measurement, hematology, clinical chemistry, urinalysis. Hematologic and nonhematologic data were assessed according to the Common Terminology Criteria for Adverse Events (CTCAE) rating scale, version 3.0 [20]. Tumor response was assessed using Response Evaluation Criteria in Solid Tumors (RECIST) 1.0 guidelines [21].

Pharmacokinetic and pharmacodynamic analyses

The concentration of encapsulated PNT100 was measured at predetermined sampling time points using the hybridization-ligation assay by Charles River Labs (Montreal, Canada). Assay validation demonstrated specificity, precision, accuracy, inter-assay variation, long-term stability, and no interference with $5 \%(\mathrm{v} / \mathrm{v})$ hemolysis in plasma with a lower limit of quantitation (LLOQ) of $3 \mathrm{ng} / \mathrm{mL}$ [16].

A nonlinear mixed effect modeling technique (NONMEM, version VI) was used to analyze plasma PNT100 data (log-transformed), allowing estimation of mean PK parameter values and inter-individual and intra-individual variability. Model parameters were estimated using the first-order conditional estimation method with interaction. The inter-individual and intra-individual variability were coded as an exponential and a proportional relationship, respectively. Three and 4 compartmental PK models with elimination from the peripheral compartment and a similar elimination rate constant were fitted to the PK data.
PNT100 plasma concentration data were also analyzed using a standard non-compartmental method to derive PK parameters for PNT100: maximum plasma concentration $\left(C_{\max }\right)$, area under the plasma concentration versus time curve (AUC), and serum half-life $\left(t_{1 / 2}\right)$.

Lymphocyte and platelets concentrations were determined from patient samples obtained at prespecified time points throughout the study and analyzed per standard clinical criteria.

\section{Statistical analysis}

Patient demographics, adverse events, clinical laboratory evaluations, and vital signs were summarized descriptively. Quantitative laboratory measurements were categorized according to normal reference ranges.

All patients that received PNT2258 were considered evaluable for the safety analysis. Patients that received at least $80 \%$ of the planned dose in cycle 1 were considered evaluable for the purpose of dose escalation.

The efficacy-evaluable population included all patients with measurable disease that received at least one full cycle of PNT2258 and had at least one post-treatment response assessment or discontinued before having a response assessment due to rapid disease progression or death. Descriptive statistics were used for plasma concentration data.

\section{Results}

Patients

Twenty-two patients were accrued and received PNT2258 at START-South Texas Accelerated Research Therapeutics, San Antonio, Texas, between September 2010 and January 2012. Table 1 summarizes patient demographics, disease characteristics, and prior treatment.

\section{Treatment}

Patients received PNT2258 at doses ranging from 1 to $150 \mathrm{mg} / \mathrm{m}^{2}$, constituting over 300 doses and sixty 21-day cycles. Over all dose levels, patients received a median of 2 completed cycles, with a range of $0-8$ cycles. The most common reasons for study discontinuation were progressive disease or symptomatic deterioration (19 patients, $86 \%)$. Two patients $(9 \%)$ discontinued therapy due to adverse event, and 1 patient (4\%) withdrew informed consent. Of the 335 planned doses of PNT2258, 314 were administered as scheduled. No patients were dose reduced for toxicity.

PNT2258 was well tolerated at dose levels 1 through $64 \mathrm{mg} / \mathrm{m}^{2}$. A single patient manifested a grade 3 DLT of 
Table 1 Patient demographics and disease characteristics

\begin{tabular}{|c|c|}
\hline Parameter & $n=22$ \\
\hline Median age (range) & $63(30-91)$ \\
\hline \multicolumn{2}{|l|}{ Gender, $n(\%)$} \\
\hline Male & $12(55)$ \\
\hline Female & $10(45)$ \\
\hline \multicolumn{2}{|l|}{ Origin } \\
\hline Caucasian & $18(82)$ \\
\hline African & $2(9)$ \\
\hline Hispanic & $2(9)$ \\
\hline \multicolumn{2}{|l|}{ ECOG performance scale, $n(\%)$} \\
\hline 0 & $3(14)$ \\
\hline 1 & $16(72)$ \\
\hline 2 & $3(14)$ \\
\hline \multicolumn{2}{|l|}{ Disease stage at entry, $n(\%)$} \\
\hline Stage IV & $22(100)$ \\
\hline \multicolumn{2}{|l|}{ Pathologic diagnosis } \\
\hline Pancreatic cancer & 5 \\
\hline Colon adenocarcinoma & 5 \\
\hline Sarcoma & 3 \\
\hline Prostate, adenocarcinoma & 2 \\
\hline Lung, non-small-cell carcinoma & 2 \\
\hline Breast, adenocarcinoma & 1 \\
\hline Endometrial & 1 \\
\hline Head and neck carcinoma & 1 \\
\hline Hepatocellular carcinoma & 1 \\
\hline Neuroendocrine tumor & 1 \\
\hline \multicolumn{2}{|l|}{ Prior treatment } \\
\hline Systemic therapy & $22(100)$ \\
\hline Surgery & $17(77)$ \\
\hline Radiotherapy & $8(36)$ \\
\hline
\end{tabular}

ECOG Eastern Cooperative Oncology Group

back/flank pain while receiving the infusion at the $85 \mathrm{mg} /$ $\mathrm{m}^{2}$ dose level, triggering expansion of the cohort to six subjects. After the occurrence of the DLT and at the discretion of the treating physician, subsequent patients could receive premedication prior to infusion with dexamethasone $10 \mathrm{mg}$, diphenhydramine $50 \mathrm{mg}$, and ranitidine $50 \mathrm{mg} \mathrm{IV}$, either alone or in combination, on day 1 of each cycle as prophylaxis for back/flank pain. This intervention limited additional occurrences of flank/back pain. No additional DLTs occurred at the $85 \mathrm{mg} / \mathrm{m}^{2}$ dose level or at $113 \mathrm{mg} / \mathrm{m}^{2}$. One DLT occurred at $150 \mathrm{mg} / \mathrm{m}^{2}$ manifesting as a grade 3 increase in AST that resulted in expansion of the cohort. No additional cycle 1 DLTs were noted at the $150 \mathrm{mg} / \mathrm{m}^{2}$ dose level. However, a patient developed a grade 4 thrombocytopenia within 30 days of study participation at the $150 \mathrm{mg} / \mathrm{m}^{2}$ dose level.
Table 2 summarizes the drug-related toxicities at all dose levels. Across all dose levels and regardless of attribution, a total of 79 adverse events and 6 serious adverse events (see section below) were reported. The most common AEs were fatigue ( 8 events in 7 subjects; 8/79, $10.1 \%$; grade range 1-2) and infusion reaction manifesting as back or flank pain (6 events in 4 subjects; 6/79; $7.6 \%$; grade range 2-3). The increase in aspartate aminotransferase at the $150 \mathrm{mg} / \mathrm{m}^{2}$ dose level was observed in a patient with metastatic disease to the liver and elevated levels resolved spontaneously within $48 \mathrm{~h}$. One patient died, as a result of disease progression, within 30 days of study participation.

\section{Efficacy}

Of the 22 patients on study, $27 \%$ (6 of 22) had stable disease at the time of the end-of-cycle $2 \mathrm{CT}$ scan. Four patients, 2 each with a diagnosis of NSCLC at the 64 and $85 \mathrm{mg} / \mathrm{m}^{2}$ dose levels and sarcoma at the 85 and $150 \mathrm{mg} /$ $\mathrm{m}^{2}$ dose levels, remained on study for $>4$ cycles (range 5-8 cycles). See Fig. 2.

\section{Pharmacokinetics}

Plasma was obtained to evaluate the pharmacokinetics of PNT2258 (Table 3). Profiles were generated from C1D1 and C1D5 dosing to calculate $C_{\max }, t_{1 / 2}$, and $\mathrm{AUC}_{\infty} . C_{\max }$ values for C1D1 and C1D5 were consistent for dose cohorts with higher doses exhibiting an increase between C1D1 $C_{\max }$ versus C1D5 $C_{\max }$ and $C_{\max }$ values in patients achieved at the higher dose levels approached those achieved in cynomolgus monkeys on C1D1.

Serum half-life $\left(t_{1 / 2}\right)$ could not be consistently calculated for C1D1 for dose cohorts 1-5, owing to rapid clearance kinetics of PNT2258 at these lower doses. $t_{1 / 2}$ at the dose levels $\geq 32 \mathrm{mg} / \mathrm{m}^{2}$ ranged from 8.7 to $58.5 \mathrm{~h}$. An increase in $t_{1 / 2}$ over C1D1 was noted for C1D5. These results are consistent with the expected prolonged clearance kinetics of PNT2258 due to saturation of the reticuloendothelial system (RES) clearance mechanisms and are similar to those noted in the toxicology studies [14, 15, 17].

The results showed consistent $T_{\max }$ of about $1.96 \mathrm{~h}$, corresponding to the end of infusion sampling (data not shown).

A dose-dependent increase in AUC was noted with exposure levels in patients. In addition, a similar trend of increasing AUC was noted between C1D1 and C1D5 with AUCs in the latter sampling approaching those observed at the highest dose level tested in preclinical toxicology studies [22]. A less than dose-proportional increase was noted at the higher dose cohorts and may be indicative of achieving the maximum exposure of PNT2258. 
Table 2 Treated patients $(n=22)$ with CTCAE 3.0 drug-related toxicities ${ }^{\mathrm{a}}$

\begin{tabular}{|c|c|c|c|c|c|c|c|c|c|c|}
\hline $\begin{array}{l}\text { Dose level and no. of } \\
\text { pts. }\end{array}$ & $\begin{array}{l}1 \mathrm{mg} / \mathrm{m}^{2} \\
n=1\end{array}$ & $\begin{array}{l}2 \mathrm{mg} / \mathrm{m}^{2} \\
n=1\end{array}$ & $\begin{array}{l}4 \mathrm{mg} / \mathrm{m}^{2} \\
\mathrm{n}=1\end{array}$ & $\begin{array}{l}16 \mathrm{mg} / \mathrm{m}^{2} \\
n=1\end{array}$ & $\begin{array}{l}64 \mathrm{mg} / \mathrm{m}^{2} \\
n=1\end{array}$ & $\begin{array}{l}85 \mathrm{mg} / \\
n=6\end{array}$ & & $\begin{array}{l}113 \mathrm{mg} / \mathrm{m}^{2} \\
n=3\end{array}$ & $\begin{array}{l}150 \mathrm{mg} / \mathrm{m}^{2} \\
n=6\end{array}$ & Total no. (\%) \\
\hline Adverse event & $\begin{array}{l}\mathrm{G} 1 / 2 \\
n(\%)\end{array}$ & $\begin{array}{l}\mathrm{G} 1 / 2 \\
n(\%)\end{array}$ & $\begin{array}{l}\mathrm{G} 1 / 2 \\
n(\%)\end{array}$ & $\begin{array}{l}\mathrm{G} 1 / 2 \\
n(\%)\end{array}$ & $\begin{array}{l}\mathrm{G} 1 / 2 \\
n(\%)\end{array}$ & $\begin{array}{l}\mathrm{G} 1 / 2 \\
n(\%)\end{array}$ & $\begin{array}{l}\mathrm{G} 3 \\
n(\%)\end{array}$ & $\begin{array}{l}\mathrm{G} 1 / 2 \\
n(\%)\end{array}$ & $\begin{array}{l}\mathrm{G} 1 / 2 \\
n(\%)\end{array}$ & \\
\hline $\begin{array}{l}\text { Infusion reaction } \\
\text { (i.e., back/flank } \\
\text { pain) }\end{array}$ & & & & & $1(4)$ & $1(4)$ & $1(4)$ & $2(9)$ & $1(4)$ & $6(27)$ \\
\hline Nausea & & $1(4)$ & $1(4)$ & $1(4)$ & & & & & $1(4)$ & $4(18)$ \\
\hline Vomiting & & $1(4)$ & & & & $1(4)$ & & & & $2(9)$ \\
\hline Diarrhea & $1(4)$ & & & & & & & & $1(4)$ & $2(9)$ \\
\hline Increased AST & & & & & & & & & $1(4)$ & $1(4)$ \\
\hline Thrombocytopenia & & & & & & & & & $1(4)$ & $1(4)$ \\
\hline
\end{tabular}

$G r$ grade, $p t s$ patients, no number, $m g$ milligrams, $m$ meter

a Listed adverse events are those assessed by the investigators as possible, probably or definitely related to study drug collected from the first dose of study drug until 30 days after discontinuation from the study. Patients are counted only once per event, with the highest experienced grade noted. No drug-related toxicity was reported in 2 or more patients at the 8 and $32 \mathrm{mg} / \mathrm{m}^{2}$ dose levels. Only toxicities reported in 2 or more patients over all cycles are reported with the exceptions stated below. A single grade 4 thrombocytopenia was noted during cycle 2 in the highest dose tested (i.e., $150 \mathrm{mg} / \mathrm{m}^{2}$ ). A single grade 3 toxicity of increased AST occurred at the $150 \mathrm{mg} / \mathrm{m}^{2}$ dose level

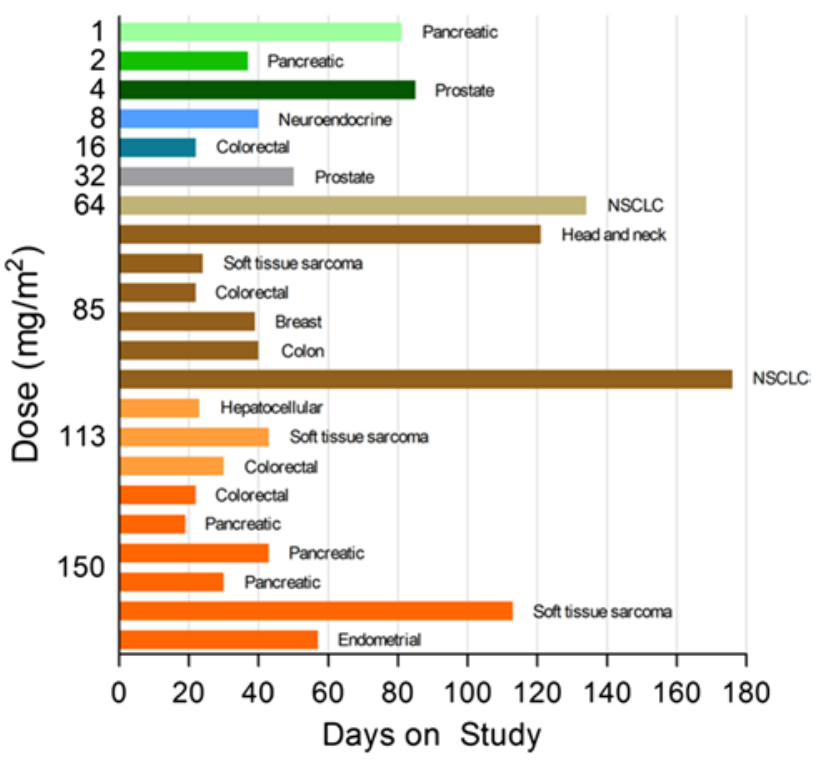

Fig. 2 Days on study for each subject as a function of dose of PNT2258 administered. Patient cancer diagnosis is shown to the right of the bars

The exposure levels (AUCs) in patients at doses at or above $32 \mathrm{mg} / \mathrm{m}^{2}$ (range $29,279-1,151,961 \mathrm{ng} \mathrm{h} /$ $\mathrm{ml}$ ) exceeded levels at which preclinical antitumor effects were observed in xenograft studies $(22,377 \mathrm{ng} \mathrm{h} / \mathrm{ml})[1,22]$.

Pharmacodynamics

Figure 3a illustrates lymphocyte concentrations in patients receiving PNT2258. Maximum decrease and leveling of lymphocytes concentrations occurred within hours of the onset of PNT2258 infusion.

As shown in Fig. 3b, platelet levels decreased in patients after exposure to PNT2258 with nadir at approximately 9 days post-onset of infusion. The decrease was generally $\leq$ grade 1 and transient in nature, with spontaneous resolution without the need for transfusion or other supportive measures and without evidence of bleeding diathesis.

\section{Discussion}

Progress in cancer therapeutics requires development and evaluation of novel strategies for drug delivery and interference of tumor cell signaling. One such novel strategy is the delivery of oligonucleotides into tumors in order to influence regulation of the cancer genome. PNT2258 is a first-in-class agent where a native unmodified DNA (24base) oligonucleotide is delivered to a nuclear genomic target via a protective liposomal nanoparticle and the first to target the regulatory upstream region of the BCL2 gene in this manner. Although other oligonucleotide constructs have been proposed and evaluated in clinic (although none targeting nuclear DNA), successful systemic delivery has been an issue and the complex chemical nature of these constructs has negatively influenced their clinical toxicity profile [7, 23]. DNA oligonucleotide-mediated suppression of genomic DNA (i.e., prior to transcription) could provide a more efficient and less toxic means of down-regulating oncogene expression and promotion of tumor killing when compared to standard cytotoxic therapy, post-translational targeting of mRNA (via RNA-based oligonucleotides), or 
Table 3 PNT2258 plasma pharmacokinetic parameters following day 1 and 5 dosing (2-hour IV infusion)

\begin{tabular}{|c|c|c|c|c|c|c|c|c|}
\hline \multirow[t]{2}{*}{ Dose $\mathrm{mg} / \mathrm{m}^{2}$} & \multicolumn{4}{|l|}{ Day 1} & \multicolumn{4}{|l|}{ Day 5} \\
\hline & No. of patients & $C_{\max }(\mathrm{ng} / \mathrm{mL})$ & $T_{1 / 2}(\mathrm{~h})$ & $\mathrm{AUC}_{\infty}(\mathrm{ng} \mathrm{h} / \mathrm{mL})$ & No. of patients & $C_{\max }(\mathrm{ng} / \mathrm{mL})$ & $T_{1 / 2}(\mathrm{~h})$ & $\mathrm{AUC}_{\infty}(\mathrm{ng} \mathrm{h} / \mathrm{mL})$ \\
\hline 1 & 1 & 15.87 & 334.4 & 1,559 & 1 & 14.09 & - & - \\
\hline 2 & 1 & 28.02 & - & - & 1 & 32.24 & 47.1 & 1,313 \\
\hline 4 & 1 & 39.55 & - & - & 1 & 98.30 & 82.2 & 7,404 \\
\hline 8 & 1 & 132.26 & 74.1 & 1,888 & 1 & 97.10 & 46.0 & 2,550 \\
\hline 16 & 1 & 317.33 & - & - & 1 & 522.36 & 45.1 & 6,731 \\
\hline 32 & 1 & 894.32 & 21.9 & 29,279 & 1 & $2,477.54$ & 58.5 & 131,853 \\
\hline 64 & 1 & $5,306.63$ & 10.9 & 57,543 & 1 & $8,141.03$ & 35.1 & 193,421 \\
\hline 85 & 6 & $7,895(35)$ & $27.8(73)$ & $146,685(67)$ & 6 & $12,311(54)$ & $50.3(27)$ & $607,765(75)$ \\
\hline 113 & 3 & $29,222(40)$ & $10.2(42)$ & $204,148(61)$ & 3 & $42,125(91)$ & $32.1(26)$ & 849,077 (123) \\
\hline 150 & 6 & $28,943(39)$ & 8.7 (57) & 203,879 (49) & 6 & $35,926(43)$ & $26.8(47)$ & $1,151,961(60)$ \\
\hline
\end{tabular}

Numbers in parentheses indicate coefficient of variation (\%). - indicates data not available

$\mathrm{AUC}_{\infty}$, area under the concentration-time curve from zero to infinity; $\mathrm{C}_{\text {max }}$, peak (maximum) plasma concentration; $\mathrm{t}_{1 / 2}$, half-life; IV, intravenous
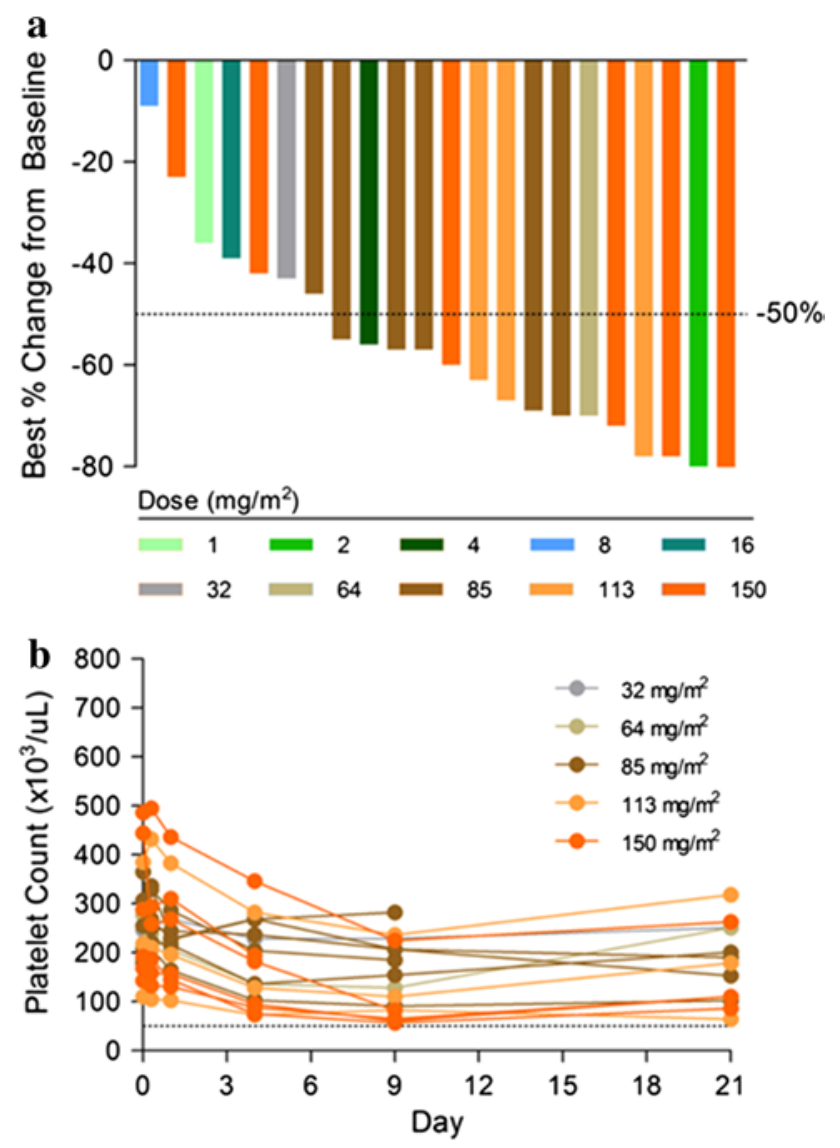

Fig. 3 a First-cycle lymphocyte nadir (i.e., percent maximum decline from baseline) as a function of dose. b Cycle 1 platelet levels

the inhibition of proteins (via small molecule protein inhibitors) [7, 24-36]. Further, inhibition of proteins by small molecule inhibitors has resulted in "off-target" toxicity, as has been the case with other agents, including previously tested BCL2-targeted therapeutics [27, 29, 32, 34-42].

PNT2258, and other related DNAi molecules, allows for clinical examination of whether targeting the upstream "regulatory" areas of the tumor genome with DNA oligonucleotides could be safe and tolerable and result in clinical activity without the characteristic toxicities of RNA-based oligonucleotides, cytotoxic, and small molecule protein inhibitor therapeutic approaches [43, 44].

This phase 1 study of PNT2258 allows for the following conclusions: (1) PNT2258 administered intravenously on days 1 through 5 of a 21-day cycle is well tolerated through doses of $150 \mathrm{mg} / \mathrm{m}^{2}$. (2) PNT2258 has an acceptable safety profile without evidence of thrombocytopenia or neutropenia at the doses tested. (3) Pharmacologic studies confirmed that doses $>32 \mathrm{mg} / \mathrm{m}^{2}$ resulted in human AUC levels above that required for anti-tumor effect in preclinical xenograft studies of BCL2-dependent tumors. (4) Human exposure levels exceeded that seen with other oligonucleotide drugs by 10-100-fold [45]. (5) PNT2258 administration resulted in decreases in lymphocyte and platelets counts, and (6) PNT2258 administration resulted in systemic delivery and was not restricted to the liver. Lastly, disease control was noted in $27 \%$ (6 of 22) patients receiving PNT2258 as indicated by $>2$ cycles of disease stabilization in this treatment-refractory population.

Preclinical results using human tumor xenograft-bearing mice confirmed robust single-agent anti-BCL2 response in the WSU-DLCL model, a NHL line with $t(14,18)$ [13]. Given the relatively wide dose range between the corresponding minimally effective exposure in the xenograft model (i.e., the $32 \mathrm{mg} / \mathrm{m}^{2}$ dose level in humans) and the maximum tested dose of $150 \mathrm{mg} / \mathrm{m}^{2}$, it suggests that additional PNT2258 doses and schedules could be explored in 
addition to the one reported here. There were no clinically unmanageable grade 3 or 4 toxicities, even in this heavily pre-treated population at any dose level tested.

This intravenously administered agent displayed favorable pharmacologic features with relatively long (i.e., 1-2 day) half-life consistent with the goal of maximum exposure of the DNA-containing liposome nanoparticle to all tissues in the body and without evidence of cumulative toxicity secondary to the 5-day infusion schedule or evidence of significant hepatic sequestration.

While patients entering this pilot phase 1 trial of PNT2258 were not subjected to biopsy and therefore not preselected on the basis of their BCL2 expression status, the results of this trial are encouraging and indicate a need for further exploration of PNT2258 in patients diagnosed with BCL2-dependent tumors. On the basis of the results of this study, a phase 2 study (NCT01733238) has been initiated to explore the utility of PNT2258 as a single agent in patients with relapsed or refractory NHL.

Acknowledgments We thank the patients and their families for graciously participating in this study. The authors would also like to thank Abhishek Manjunathan for his help in preparing the manuscript. Research supported by ProNAi Therapeutics, Inc., Plymouth, MI.

Conflict of interest Richard A. Messmann, Michael Woolliscroft, Shari Gaylor, Wendi V. Rodrigueza and Mina Sooch are employees and shareholders of ProNAi Therapeutics, Inc. Charles L. Bisgaier was an employee and is currently a Director and share holder of ProNAi Therapeutics, Inc. Mina Sooch is a Director of ProNAi Therapeutics, Inc. The other authors disclosed no potential conflicts of interest.

Open Access This article is distributed under the terms of the Creative Commons Attribution License which permits any use, distribution, and reproduction in any medium, provided the original author(s) and the source are credited.

\section{References}

1. (2012) PK analysis for a phase 1 study of PNT2258 in patients with advanced solid tumors. Internal document (ProNAi Therapeutics) conducted by VEEDA Clinical Research, Brussels, Belgium

2. Adams JM, Cory S (2007) Bcl-2-regulated apoptosis: mechanism and therapeutic potential. Curr Opin Immunol 19(5):488-496. doi:10.1016/j.coi.2007.05.004

3. Cory S, Adams JM (2005) Killing cancer cells by flipping the Bcl-2/Bax switch. Cancer Cell 8(1):5-6. doi:10.1016/j.ccr.2005. 06.012

4. Davids MS, Letai A (2012) Targeting the B-cell lymphoma/ leukemia 2 family in cancer. J Clin Oncol 30(25):3127-3135. doi:10.1200/JCO.2011.37.0981

5. The SMARTICLES ${ }^{\circledR}$ technology: enabling systemic DNA therapeutics. http://pharmalicensing.com/public/outlicensing/view/ 12158/the-smarticles-technology-enabling-systemic-dnatherapeutics

6. Adami RC, Seth S, Harvie P, Johns R, Fam R, Fosnaugh K, Zhu T, Farber K, McCutcheon M, Goodman TT, Liu Y, Chen Y,
Kwang E, Templin MV, Severson G, Brown T, Vaish N, Chen F, Charmley P, Polisky B, Houston ME Jr (2011) An amino acidbased amphoteric liposomal delivery system for systemic administration of siRNA. Mol Ther J Am Soc Gene Ther 19(6):11411151. doi:10.1038/mt.2011.56

7. Seth S, Johns R, Templin MV (2012) Delivery and biodistribution of siRNA for cancer therapy: challenges and future prospects. Ther deliv 3(2):245-261

8. Rodrigueza WV, Mohammad R, McGovern JP, Wick MJ, Rasco D, Tolcher AW, Bisgaier CL (2012) Effect of PNT2258 combinations with docetaxel, dacarbazine, or vemurafenib on the A375 melanoma xenograft. In: AACR 103rd Annual Meeting 2012, Chicago, IL, 31 Mar-4 Apr, 2012

9. (2010) PNT100 Expression in preclinical murine samples. Internal document (ProNAi Therapeutics)

10. Nicolaou AE (2009) Mode of action of PNT100 (trans: Department P). Internal document (ProNAi Therapeutics) conducted by Novosom AG

11. Thurman RE, Rynes E, Humbert R, Vierstra J, Maurano MT, Haugen E, Sheffield NC, Stergachis AB, Wang H, Vernot B, Garg K, John S, Sandstrom R, Bates D, Boatman L, Canfield TK, Diegel M, Dunn D, Ebersol AK, Frum T, Giste E, Johnson AK, Johnson EM, Kutyavin T, Lajoie B, Lee BK, Lee K, London D, Lotakis D, Neph S, Neri F, Nguyen ED, Qu H, Reynolds AP, Roach V, Safi A, Sanchez ME, Sanyal A, Shafer A, Simon JM, Song L, Vong S, Weaver M, Yan Y, Zhang Z, Zhang Z, Lenhard B, Tewari M, Dorschner MO, Hansen RS, Navas PA, Stamatoyannopoulos G, Iyer VR, Lieb JD, Sunyaev SR, Akey JM, Sabo PJ, Kaul R, Furey TS, Dekker J, Crawford GE, Stamatoyannopoulos JA (2012) The accessible chromatin landscape of the human genome. Nature 489(7414):75-82. doi:10.1038/nature11232

12. Schmitz R, Renne C, Rosenquist R, Tinguely M, Distler V, Menestrina F, Lestani M, Stankovic T, Austen B, Brauninger A, Hansmann ML, Kuppers R (2005) Insights into the multistep transformation process of lymphomas: IgH-associated translocations and tumor suppressor gene mutations in clonally related composite Hodgkin's and non-Hodgkin's lymphomas. Leukemia 19(8):1452-1458. doi:10.1038/sj.leu.2403841

13. Technical Report 2-ProNAi Research Protocol 236: efficacy evaluation of PNT2258 stored frozen and stored refrigerated in WSU-DLCL2 xenograft bearing CB-17 SCID mice in combination with rituximab. Kalamazoo, MI

14. (2010) A Repeat-Dose Safety Pharmacology Study (with evaluation of cardiovascular, respiratory, and central nervous systems) of PNT2258 Administered to Cynomolgus Monkeys by Intravenous Infusion. ProNAi Therapeutics report number CRL (Charles River Labs) LLF00001

15. (2010) A 4-Week (2-Cycle) Intravenous Toxicity and Pharmacokinetic/Tissue Distribution Study of PNT2258 in Rats. ProNAi Therapeutics report number MPI (MPI Research) 1208-002

16. Legakis HC, Tran P, Rodrigueza WV, Bisgaier C (2012) Development and validation of a hybridization-ligation assay for the quantitative measurement of PNT100, the oligonucleotide component present in liposomal formulation PNT2258, in human plasma. Paper presented at the 14th annual TIDES conference: oligonucleotide and peptide therapeutics from research through commercialization, Las Vegas

17. (2010) A 4-Week (2-Cycle) Intravenous Toxicity and Pharmacokinetic/Tissue Distribution Study of PNT2258 and an Active Analogue in Cynomolgus Monkeys. ProNAi Therapeutics report number MPI (MPI Research) 1208-003

18. Senior JH (1987) Fate and behavior of liposomes in vivo: a review of controlling factors. Crit Rev Ther Drug Carrier Syst 3(2):123-193

19. http://www.clinicaltrials.gov/ct2/show/NCT01191775?term $=\mathrm{PN}$ $\mathrm{T} 2258 \& \mathrm{rank}=1$ 
20. http://ctep.cancer.gov/protocolDevelopment/electronic_applications/ docs/ctcaev3.pdf

21. http://www.eortc.be/recist/

22. Analysis of pharmacokinetic data CRL 345764. Clinical Reference Laboratory, Lenexa, Kansas 66215 USA

23. Seth S, Matsui Y, Fosnaugh K, Liu Y, Vaish N, Adami R, Harvie P, Johns R, Severson G, Brown T, Takagi A, Bell S, Chen Y, Chen F, Zhu T, Fam R, Maciagiewicz I, Kwang E, McCutcheon M, Farber K, Charmley P, Houston ME Jr, So A, Templin MV, Polisky B (2011) RNAi-based therapeutics targeting survivin and PLK1 for treatment of bladder cancer. Mol Ther J Am Soc Gene Ther 19(5):928-935. doi:10.1038/mt.2011.21

24. Ackler S, Mitten MJ, Chen J, Clarin J, Foster K, Jin S, Phillips DC, Schlessinger S, Wang B, Leverson JD, Boghaert ER (2012) Navitoclax (ABT 263) and bendamustine \pm rituximab induce enhanced killing of non-Hodgkin's lymphoma tumors in vivo. $\mathrm{Br}$ J Pharmacol. doi:10.1111/j.1476-5381.2012.02048.x

25. Chen J, Jin S, Abraham V, Huang X, Liu B, Mitten MJ, Nimmer P, Lin X, Smith M, Shen Y, Shoemaker AR, Tahir SK, Zhang H, Ackler SL, Rosenberg SH, Maecker H, Sampath D, Leverson JD, Tse C, Elmore SW (2011) The Bcl-2/Bcl-X(L)/Bcl-w inhibitor, navitoclax, enhances the activity of chemotherapeutic agents in vitro and in vivo. Mol Cancer Ther 10(12):2340-2349. doi:10.1158/1535-7163.MCT-11-0415

26. Mattoo AR, Fitzgerald DJ (2012) Combination treatments with ABT-263 and an immunotoxin produce synergistic killing of ABT-263-resistant small cell lung cancer cell lines. Int J Cancer. doi:10.1002/ijc. 27732

27. Rudin CM, Hann CL, Garon EB, Ribeiro de Oliveira M, Bonomi PD, Camidge DR, Chu Q, Giaccone G, Khaira D, Ramalingam SS, Ranson MR, Dive C, McKeegan EM, Chyla BJ, Dowell BL, Chakravartty A, Nolan CE, Rudersdorf N, Busman TA, Mabry MH, Krivoshik AP, Humerickhouse RA, Shapiro GI, Gandhi L (2012) Phase II study of single-agent navitoclax (ABT-263) and biomarker correlates in patients with relapsed small cell lung cancer. Clin Cancer Res 18(11):3163-3169. doi:10.1158/1078-0432.CCR-11-3090

28. Sakuma Y, Tsunezumi J, Nakamura Y, Yoshihara M, Matsukuma S, Koizume S, Miyagi Y (2011) ABT-263, a Bcl-2 inhibitor, enhances the susceptibility of lung adenocarcinoma cells treated with Src inhibitors to anoikis. Oncol Rep 25(3):661-667. doi:10.3892/or2010.1123

29. Schoenwaelder SM, Jackson SP (2012) Bcl-xL-inhibitory BH3 mimetics (ABT-737 or ABT-263) and the modulation of cytosolic calcium flux and platelet function. Blood 119(5):1320-1321. doi:10.1182/blood-2011-10-387399 (author reply 1321-1322)

30. Shi J, Zhou Y, Huang HC, Mitchison TJ (2011) Navitoclax (ABT-263) accelerates apoptosis during drug-induced mitotic arrest by antagonizing Bcl-xL. Cancer Res 71(13):4518-4526. doi:10.1158/0008-5472.CAN-10-4336

31. Tan N, Malek M, Zha J, Yue P, Kassees R, Berry L, Fairbrother WJ, Sampath D, Belmont LD (2011) Navitoclax enhances the efficacy of taxanes in non-small cell lung cancer models. Clin Cancer Res 17(6):1394-1404. doi:10.1158/1078-0432.CCR-10-2353

32. Tse C, Shoemaker AR, Adickes J, Anderson MG, Chen J, Jin S, Johnson EF, Marsh KC, Mitten MJ, Nimmer P, Roberts L, Tahir SK, Xiao Y, Yang X, Zhang H, Fesik S, Rosenberg SH, Elmore SW (2008) ABT-263: a potent and orally bioavailable Bcl-2 family inhibitor. Cancer Res 68(9):3421-3428. doi:10.1158/00085472.CAN-07-5836

33. Vogler M, Dickens D, Dyer MJ, Owen A, Pirmohamed M, Cohen GM (2011) The B-cell lymphoma 2 (BCL2)-inhibitors, ABT-737 and ABT-263, are substrates for P-glycoprotein. Biochem Biophys Res Commun 408(2):344-349. doi:10.1016/j.bbrc.2011.04.043
34. Walensky LD (2012) From mitochondrial biology to magic bullet: navitoclax disarms BCL-2 in chronic lymphocytic leukemia. J Clin Oncol 30(5):554-557. doi:10.1200/JCO.2011.37.9339

35. Wilson WH, O'Connor OA, Czuczman MS, LaCasce AS, Gerecitano JF, Leonard JP, Tulpule A, Dunleavy K, Xiong H, Chiu YL, Cui Y, Busman T, Elmore SW, Rosenberg SH, Krivoshik AP, Enschede SH, Humerickhouse RA (2010) Navitoclax, a targeted high-affinity inhibitor of BCL-2, in lymphoid malignancies: a phase 1 dose-escalation study of safety, pharmacokinetics, pharmacodynamics, and antitumour activity. Lancet Oncol 11(12):1149-1159. doi:10.1016/S1470-2045(10)70261-8

36. Wong M, Tan N, Zha J, Peale FV, Yue P, Fairbrother WJ, Belmont LD (2012) Navitoclax (ABT-263) reduces Bcl-x(L)-mediated chemoresistance in ovarian cancer models. Mol Cancer Ther 11(4):1026-1035. doi:10.1158/1535-7163.MCT-11-0693

37. Davids MS, Letai A (2013) ABT-199: taking dead aim at BCL-2. Cancer Cell 23(2):139-141. doi:10.1016/j.ccr.2013.01.018

38. Gandhi L, Camidge DR, Ribeiro de Oliveira M, Bonomi P, Gandara D, Khaira D, Hann CL, McKeegan EM, Litvinovich E, Hemken PM, Dive C, Enschede SH, Nolan C, Chiu YL, Busman T, Xiong H, Krivoshik AP, Humerickhouse R, Shapiro GI, Rudin CM (2011) Phase I study of Navitoclax (ABT-263), a novel Bcl-2 family inhibitor, in patients with small-cell lung cancer and other solid tumors. J Clin Oncol 29(7):909-916. doi:10.1200/ JCO.2010.31.6208

39. Roberts AW, Seymour JF, Brown JR, Wierda WG, Kipps TJ, Khaw SL, Carney DA, He SZ, Huang DC, Xiong H, Cui Y, Busman TA, McKeegan EM, Krivoshik AP, Enschede SH, Humerickhouse R (2012) Substantial susceptibility of chronic lymphocytic leukemia to BCL2 inhibition: results of a phase I study of navitoclax in patients with relapsed or refractory disease. J Clin Oncol 30(5):488-496. doi:10.1200/JCO.2011.34.7898

40. Souers AJ, Leverson JD, Boghaert ER, Ackler SL, Catron ND, Chen J, Dayton BD, Ding H, Enschede SH, Fairbrother WJ, Huang DC, Hymowitz SG, Jin S, Khaw SL, Kovar PJ, Lam LT, Lee J, Maecker HL, Marsh KC, Mason KD, Mitten MJ, Nimmer PM, Oleksijew A, Park CH, Park CM, Phillips DC, Roberts AW, Sampath D, Seymour JF, Smith ML, Sullivan GM, Tahir SK, Tse C, Wendt MD, Xiao Y, Xue JC, Zhang H, Humerickhouse RA, Rosenberg SH, Elmore SW (2013) ABT-199, a potent and selective BCL-2 inhibitor, achieves antitumor activity while sparing platelets. Nat Med 19(2):202-208. doi:10.1038/nm.3048

41. Basit F, Cristofanon S, Fulda S (2013) Obatoclax (GX15-070) triggers necroptosis by promoting the assembly of the necrosome on autophagosomal membranes. Cell Death Differ. doi:10.1038/ cdd.2013.45

42. Herbst RS, Frankel SR (2004) Oblimersen sodium (Genasense bcl-2 antisense oligonucleotide): a rational therapeutic to enhance apoptosis in therapy of lung cancer. Clin Cancer Res $10(12 \mathrm{Pt}$ 2):4245s-4248s. doi:10.1158/1078-0432.CCR-040018

43. Rasco DW, Patnaik A, Amaya A, Gaylor S, Moore T, Izbicka E, Streeper R, Rodrigueza W, Messmann R, Tolcher A (2012) A study of PNT2258 (DNA-targeted Blocker of BCL2 Expression) in patients with advanced solid tumors. Eur J Cancer 48(Suppl 6):191. doi:10.1016/S0959-8049(12)72417-6

44. Rasco DW, Papadopoulos K, Wick M, Amaya A, Izbicka E, Streeper R, Louden C, Woolliscroft M, Sooch M, Messmann RA, Rodrigueza WV (2013) Effect of PNT2258, an anti-BCL2 DNAinterference drug, on tumor growth and immunological markers in mice and humans. In: American association of cancer research annual meeting, Washington, DC, 18 January 2013

45. Lightfoot HL, Hall J (2012) Target mRNA inhibition by oligonucleotide drugs in man. Nucleic Acids Res 40(21):10585-10595. doi:10.1093/nar/gks861 